\title{
Discurso, ideologia e sujeito: tensionando fronteiras
}

\section{Alexandre Fleming Vasques Bastos}

Graduado em História pela Universidade Federal de Alagoas (Ufal), Mestre em Educaçāo pelo

Programa de Pós-Graduação em Educaçāo (PPGE/Ufal) e Doutorando em Lingūística pelo

Programa de Pós-Graduaçāo em Letras e

Lingüística pela Universidade Federal de Alagoas (PPGLL/Ufal).

Resumo: Exposição dos caminhos da interlocução teórica da $A D$ de linha francesa coın o campo marxista, a cujo referencial analíticometodológico são acrescentadas visadas teóricas de Lukács e de Bakhtin através das quais se elegem, como conceitos nucleares, a ideologia, o sujeito e a dimensão histórico-social do discurso, possibilitando o acesso ao lugar social de onde falam os sujeitos e, com base nisso, uma reflexão sobre essas categorias centrais, pontos de permanente tensão nesse campo.

Palavras-chave: discurso; ideologia; sujeito

Resumen: Exposición de los caminos de la interlocución teórica del $A D$ de línea francesa con el campo marxista a cuyo referencial analíticometodológico acrecentamos contribuciones teóricas de Bajtín y Lukács a través de las cuales se eligen como conceptos nucleares la ideología, el sujeto, y la dimensión histórico-social del discurso, permitiendo el acceso al lugar social desde donde hablan los sujetos, y haciendo una reflexión acerca de esas categorías centrales, que son puntos de tensión constante en ese campo.

Palabras-clave: discurso; ideologia; sujeto 



\section{Demarcando o caminho}

Antes de iniciarmos algumas conceituações de forma sistemática sobre os principais elementos discurso, ideologia e sujeito - , constitutivos, a nosso ver, da Análise do Discurso a que nos filiamos, é importante, desde já, afirmar que esses são pontos de permanente tensão no campo da AD. Na perspectiva do lugar teórico a partir do qual falamos, esses são conceitos que, a partir das escolhas que o analista faz, possibilitam a sua aproximação ou o seu distanciamento de tal ou qual perspectiva teórica. Assim, já deixamos transparecer nosso entendimento de que a Análise do Discurso é uma corrente teórico-metodológica que, ao longo de sua trajetória na França e no Brasil, tem "contraído matrimônio" com concepções diversas não só de sujeito, de ideologia e de discurso, mas também com diferentes perspectivas teóricometodológicas desse campo de saber.

Para Orlandi (2005, p.9), "haverá sempre, por mais estabelecida que já seja a disciplina, muitas maneiras de apresentá-la e sempre a partir de perspectivas que mostram menos a variedade da ciência que a presença da ideologia". De fato, nosso percurso tentará expor uma posição, um lugar de enunciação no campo da AD, não havendo espaço para uma análise das diversas variações dessa corrente, das diferentes perspectivas ideológicas.

A teoria do discurso instaurada pelo francês Michel Pêcheux nos idos do final da década de 60 do século XX, ainda que surgida de um mesmo tronco, tomou diferentes rumos, distanciando-se de sua perspectiva inicial ancorada no materialismo histórico, ainda que althusseriano. A própria AD nasce, como afirma Cavalcante (2002, p.42), "em oposição aos dois quadros teóricos existentes na França - o estruturalismo saussuriano e o gerativismo chomskyano - e como ruptura epistemológica com a ideologia que dominava as ciências humanas à época - o psicologismo".

Desse modo, tratar desses conceitos torna-se uma missão que por vezes os ares do contexto-histórico levaram 
a posições diversificadas, ora estruturalistas, ora pósmodernas, gerando grandes conflitos. Esses conflitos tornam-se ainda mais tencionados, quando delimitamos o discurso como o objeto privilegiado da análise.

Como, então, trafegar numa zona tão conflitante? Mais pertinente seria perguntar para quais lugares o contexto-histórico tende a levar e "oportunamente" seguilo, já que, na atualidade, se encontram em expansão o academicismo relativista e o ecletismo pós-moderno. Nossa posição, entretanto, inegavelmente, reconhece a intervenção das fortes e insistentes rajadas do tempo e do contexto-histórico. Sabemos também que nem "todo caminho dá na venda" e que só aqueles que sabem aonde querem chegar têm chances de escolher seus caminhos e enfrentar as turbulências, pois reconhecem que uma leve brisa às vezes se transforma num vendaval.

Assim, mesmo evitando firmar nossa posição precipitadamente, usando de rótulos, entendemos ser necessário demarcar aqui nossa interlocução com certos autores como Bakhtin e Lukács, e, conseqüentemente, com seus respectivos percursos, embora, desde já, consideremos que o caminho pelo qual optamos apresentase, na atualidade, em plena construção e que trilhar por linhas tão tênues exige no mínimo certa cautela.

Temos consciência, pois, de que definir de forma sistematizada a relação entre discurso, ideologia e sujeito é uma tarefa extremamente complexa e perigosa. Corremos o risco dos reducionismos, das apresentações simplórias e apressadas. No entanto, também não queremos tornar o caminho de difícil acesso, denso, pesado, nebuloso. A dialética existente no interior dessa relação (discurso, ideologia e sujeito) nos permite afirmar a impossibilidade de um ocorrer sem a existência dos outros, por serem partes inelimináveis de um todo. Ainda assim, essa aproximação entre tais elementos não nos impede de identificar no discurso o objeto privilegiado de análise da realidade, principalmente por ser ele produto e produtor, presente em todas as relações sociais e indispensáveis ao 
ser social, constituindo-se como objeto de estudo da Análise do Discurso.

\section{Considerações sobre o discurso}

O que entendemos por discurso? Como já explicitamos anteriormente, existem diferentes lugares teóricos que sinalizam diversas formas de concebê-lo. Não temos, nesse trabalho, a pretensão de examinar exaustivamente as diferentes concepções existentes nesse campo, por não considerar essa análise relevante para o referido trabalho, e, também, pela polêmica que algumas concepções têm suscitado, quer nas diversas áreas de estudos da linguagem, quer nas diversas tendências de cada uma dessas áreas.

Limitar-nos-emos a explicitar a noção de discurso que assumimos a partir da ancoragem teórica pela qual optamos. Pinçando algumas definições nesse campo, encontramos em Maingueneau (2000, p.43) que o discurso é "a atividade de sujeitos inscritos em contextos determinados". Em Orlandi (2005, p.21) "discurso é efeito de sentidos entre locutores”. Para Magalhães (2003, p.75), "é uma práxis humana que só pode ser compreendida a partir do entendimento das contradições sociais que possibilitam a sua objetivação". Em Pêcheux (1990, p.56), temos que "todo discurso é índice potencial de uma agitação nas filiações sócio-históricas, [...] na medida em que ele constitui ao mesmo tempo um efeito dessas filiações e um trabalho mais ou menos consciente". Ainda segundo Pêcheux, o discurso é acontecimento que articula uma atualidade a uma rede de memória. Segundo Cavalcante (2003, p.45),

o discurso é práxis, resultado e possibilidade das relações sociais, [...] produto das relações do indivíduo consigo mesmo e com os outros indivíduos. Produzido socialmente, em um determinado momento histórico, para responder às necessidades postas nas relações entre os homens 
para a produção e reprodução de sua existência, carrega o histórico e o ideológico dessas relações.

Assim sendo, podemos assumir que todo discurso é ideológico, uma vez que, ao produzi-lo, o sujeito o faz a partir de um lugar social, de uma perspectiva ideológica. Todo discurso tem a ver com o tipo de relação do sujeito no processo de produção da vida de uma sociedade. Daí a necessidade de considerar as condições de produção do discurso que compreendem, fundamentalmente, os sujeitos em constante relação com a cultura, com a sociedade e com a economia de um determinado momento histórico, pois todo discurso é histórico. Segundo Amaral (2005, p. 18),

tratar das condições de produção de discurso (CPD) requer compreender o processo das determinações sociais, políticas e econômicas da produção intelectual em geral, designada pela teoria marxista como formas de consciências ou formações ideológicas. Essa produção é concretamente organizada e explicitada em forma de discursos. É como discurso que ela [...] atua nas mesmas relações sociais que a originam.

Assim como Bakhtin, Pêcheux também considera que a linguagem, enquanto materialidade discursiva, não serve apenas como instrumento de comunicação, é uma produção social, é o lugar privilegiado de manifestação da ideologia. Nesse sentido, as condições de produção do discurso levam em consideração não apenas o contexto imediato (situação da enunciação), mas também as determinações sócio-históricas, tanto as amplas quanto as restritas. Nestas, compreendem-se os sujeitos, a produção de acontecimentos discursivos e as contradições ideológicas presentes na materialidade dos discursos, ou seja, a forma como esses acontecimentos significam e afetam os sujeitos nas diferentes posições políticas na 
nossa sociedade. Isso pressupõe levar em consideração, primordialmente, as relações sociais e a luta de classes, ou seja, as condições materiais específicas que possibilitaram a produção do discurso.

$\mathrm{Na}$ concepção marxista, o motor do processo histórico numa sociedade desigual encontra-se na luta entre as classes sociais. Marx e Engels, em célebre passagem do Manifesto do Partido Comunista (2001, p.23), sentenciavam que "a história de toda sociedade até nossos dias é a história da luta de classe". Também segundo esses autores (2004, p.48) "as idéias da classe dominante são, em todas as épocas, as idéias dominantes, ou seja, a classe que é poder material dominante da sociedade é, ao mesmo tempo, o seu poder espiritual dominante". Ao mesmo tempo, ainda que dominante, hegemônica, tal realidade não elimina a existência de outros sentidos no interior dos discursos, noutras perspectivas.

Por sua vez, Bakhtin (2004, p.47) afirma que "a classe dominante tende a conferir ao signo ideológico um caráter intangível e acima das diferenças de classe". Nesse sentido, a classe dominante busca imprimir a seu discurso a idéia de neutralidade ou de consenso acima das diferenças de classe, na tentativa de ocultar e/ou abafar os conflitos que são travados permanentemente. A própria produção historiográfica está coberta de silenciamentos, num posicionamento que visa pensar a história através de fatos "incontestáveis" e fixos no tempo e no espaço, como um velho museu de cera e não como processo conflituoso, vivo, envolvendo interesses materiais e espirituais. Bakhtin (2004 p.46-47) afirma que

o signo se torna a arena onde se desenvolve a luta de classes [...] Todo signo ideológico vivo tem, como Jano, duas faces. Toda crítica viva pode tornar-se elogio, toda verdade viva não pode deixar de parecer para alguns a maior da mentiras. Esta dialética interna do signo não se revela inteiramente [...] na realidade, não são palavras o que pronunciamos ou escutamos, 
mas verdades ou mentiras, coisas boas ou más, importantes ou triviais, agradáveis ou desagradáveis etc. A palavra está sempre carregada de um conteúdo ou de um sentido ideológico ou vivencial.

Assim, quando Bakhtin (idem, p.41) diz que "as palavras são tecidas a partir de uma multidão de fios ideológicos e servem de trama a todas as relações sociais em todos os domínios", desenvolve uma reflexão atribuindo ao signo um campo de tensão entre as classes. Logo, o sentido é constituído socialmente "mediante a encarnação material em signos [...] aquilo que nos interessa liga-se à questão de saber como a realidade determina o signo, como o signo reflete e refrata a realidade em transformação" (ibidem, p.41).

Enfim, a partir dessas reflexões consideramos que o discurso é muito mais do que comunicação e efeito de sentidos; é o encontro e o confronto social, é o reflexo e refração da totalidade; é o momento no qual os sujeitos se colocam e/ou se deslocam entre os demais e as suas ideologias, conscientes ou não desse feito.

\section{Ideologia e sujeito}

Reiteradas vezes encontramos em livros que tratam da ideologia uma advertência peremptória a respeito das mais diversas possibilidades de entendimento, utilização e significação do termo. Michael Löwy (apud KONDER 2002, p. 9) corrobora essa afirmação quando diz que

existem poucos conceitos na história da ciência social moderna que sejam tão enigmáticos e polissêmicos como esse de ideologia. Ao longo dos últimos dois séculos ele se tornou objeto de acumulação incrível, até mesmo fabulosa de ambigüidades, paradoxos, arbitrariedades, contra-sensos e equívocos.

Dizer isso bastaria para deixar evidente que também reconhecemos as diversas formas de 
entendimento do sentido de ideologia. Não é, pois, nossa intenção um mergulho nesse oceano de significações e controvérsias. Pautaremos aqui a perspectiva de ideologia à qual nos filiamos sem tecer comentários sobre as demais concepções. No máximo, algumas questões pontuais sobre a utilização desse conceito dentro da $\mathrm{AD}$ e os principais pontos de permanente tensionamento.

Nossa filiação teórica, nesse sentido, ainda que parta da linha francesa de Análise do Discurso, que dialoga com Althusser em seu Aparelhos ideológicos de Estado, como base para o conceito de ideologia de que se utiliza Pêcheux, rompe radicalmente com tal formulação, desenvolvendo, antes, uma interlocução com Bakhtin e Lukács. A partir desses dois autores é que utilizaremos a concepção de ideologia na qual nos apoiaremos neste trabalho.

Bakhtin, em seu livro Marxismo e filosofia da linguagem (2004, p.31), alertava que "as bases de uma teoria marxista da criação ideológica [...] estão estreitamente ligadas aos problemas de filosofia da linguagem”. Assim, para iniciar a sua análise sobre a filosofia da linguagem, esse autor desenvolve alguns conceitos acerca da ideologia, principalmente no que se refere às concepções de signo ideológico. Para ele, tanto um corpo físico, um instrumento de trabalho e um produto de consumo fazem parte de uma realidade, enquanto, diferente desses, o produto ideológico, além de fazer parte de uma realidade, também reflete e refrata uma outra realidade. Nesse sentido, afirma Bakhtin (idem, p.31), "tudo que é ideológico possui um significado e remete a algo situado fora de si mesmo". Ou seja, o objeto como tal é a sua realidade mesma e é outra também, quando coberto de significados, de ideologia, quando transformado em signo ideológico. Nas palavras de Bakhtin (ibidem, p.31), "o corpo físico vale por si próprio: não significa nada e coincide com a sua própria natureza”.

Há, assim, a realidade própria do objeto e também o signo ideológico sem que haja uma fusão entre 
' Fundada em 1968, a gravadora inglesa Apple Records tinha como objetivo inicial realizar a gravação e a distribuição dos discos dos Beatles nos EUA.

${ }^{2}$ Fundada em 1976, a empresa americana Apple Inc. é uma empresa fabricante de eletrônicos, computadores e produtora de software. eles. Não existe a possibilidade de o signo tornar-se a realidade própria do objeto como também não é possível que a realidade própria do objeto se torne signo. Sempre haverá uma demarcação, delimitação, separação, distinção entre um e outro; mesmo que a aproximação seja quase que absoluta, ainda assim não se apagará tal demarcação entre eles.

Desse modo, podemos utilizar como exemplo a maçã. Como corpo físico, ela não possui um sentido preciso, porém pode tornar-se signo ideológico e refletir e refratar uma outra realidade. A maçã que Eva comeu no paraíso não deixa de ser parte da sua realidade como corpo físico, mas reflete e refrata toda uma concepção religiosa do rompimento da pureza humana com o paraíso divino, passando então a ser um signo ideológico religioso. Outra maçã que, permanecendo como parte da sua realidade própria, ou seja, como produto de consumo, passa a refletir e refratar outra realidade: é a maçã verde, por exemplo, símbolo da gravadora dos Beatles, a logomarca da empresa inglesa Apple Records, ${ }^{1}$ uma maçã verde inteira e madura. Ou, ainda, a Apple, logomarca da empresa americana Apple Inc., ${ }^{2}$ que também é uma maçã, mas com uma mordida no lado direito, simbolizando a empresa de produtos de informática, computadores e produtora de softwares.

Podemos citar vários signos ideológicos que têm como base a mesma parte da realidade — a maçã —, porém reflete e refrata uma outra realidade. Assim, a maçã como signo ideológico pode representar elementos bíblicos, gravadoras de discos, empresa de informática, a maçã do amor encontrada nos parquinhos ou, mesmo, uma armadilha da bruxa para envenenar Branca de Neve, como aparece nas fábulas infantis. Essas significações não estão na maçã vista como produto de consumo, não é da maçã que tais significações surgem, mas do signo ideológico, que é um fenômeno do mundo exterior. Embora parte de uma realidade, não é toda a realidade - acentuada ainda mais a distinção entre realidade própria do objeto e o signo 
ideológico - , o signo ideológico também reflete e refrata uma outra realidade que lhe é exterior.

Essa existência do signo ideológico como reflexo e refração da realidade, apresentando-se também como fragmento material da realidade, possibilita entender a realidade do signo como totalmente objetiva. Para Bakhtin (op.cit. p.33),

cada signo ideológico é não apenas um reflexo, uma sombra da realidade, mas também um fragmento material dessa realidade. Todo fenômeno que funciona como signo ideológico tem uma encarnação material, seja como som, como massa física, como cor, como movimento do corpo ou como outra coisa qualquer" (grifo nosso).

Em uma de suas aulas expositivas, Cavalcante ${ }^{3}$ apresentou um exemplo relacionado à música "Cálice", de Chico Buarque. Dizia ela, referindo-se à canção, ${ }^{4}$ que a música, composta e tocada durante o regime militar, ainda que a materialidade da letra possibilite a referência bíblica à crucificação de Cristo ou à simbologia religiosa empregada na missa para consagrar o vinho, também através da materialidade do som ("Cale-se, afasta de mim esse cálice!"), permite inferir outra materialidade, agora entendida como "Cale-se! Afasta de mim esse cale-se!", abrindo caminho para outro sentido: calar-se, não falar, emudecer, não dizer palavra, silenciar.

A materialidade sonora não é o elemento determinante para perceber o sentido, pois tanto "cálice" quanto "cale-se" comportam a mesma materialidade sonora. Ou seja, da mesma forma que as maçãs, como objeto físico, contêm uma base material comum, "cálice", por sua vez, na perspectiva da sonoridade, também a contém; porém, a parte da realidade da maçã é comum e remete à mesma realidade enquanto a sonorização da palavra "cálice", materializada no jogo sonoro "cálice"/ "cale-se", já possibilita outras realidades. Mas o que vai
${ }^{3}$ Professora $\mathrm{Dr}^{3}$ Maria do Socorro Aguiar de Oliveira Cavalcante, do Centro de Educação (Cedu/Ufal), do Programa de PósGraduação em Educação (PPGE/Ufal) e do Programa de PósGraduação em Letras e Lingüística (PPGLL/ Ufal).

${ }^{4}$ Existem diversos estudos disponíveis sobre a obra de Chico Buarque, dentre tantos: "O inconformismo socia no discurso de Chico Buarque", disponível em: http:// www.revistafenix.pro.br/ PDF3/Artigo\%20 Christian\% 20Alves\%20 Martins.pdf?PHPSESSID $=\mathrm{d} 1 \mathrm{fa} 1126 \mathrm{~d} 4 \mathrm{~b} 189 \mathrm{c} 4101$ 80673b8e18d2a 
${ }^{5}$ Disponível em: http:// chicobuarque.uol.com.br/ texto/index.html fazer determinar que a letra da música reflita e refrate outra realidade não é a materialidade do objeto em si mesma (som/palavra) e sim o signo ideológico, que é construído num sentido político, numa realidade posta, ou seja, nas condições históricas em que a música é produzida.

Interessante perceber que o próprio autor da canção, quando fala da sua produção no período militar, em entrevista a revista Caros amigos, (versão on-line) ${ }^{5}$, evidencia a força daquele acontecimento sobre sua obra. Chico Buarque (1998, p.23) chega a afirmar que

até preferia que não tivesse havido a necessidade de misturar política com criação artística, preferia que não tivesse existido a censura, que era uma interferência direta na criação do artista. $A$ música, mesmo a imprensa, quando você está escrevendo um artigo debaixo de censura, ela está interferindo na tua escrita, na tua criação, isso acontecia no começo dos anos 70, principalmente. Não foi uma escolha minha. (grifo nosso)

O exemplo acima serve-nos para uma breve análise da palavra como fenômeno ideológico. Ou seja, a palavra como signo. Para que a palavra "cálice" pudesse transformar-se em "cale-se", melhor dizendo, para que o signo "cálice" pudesse ser re-significado para "cale-se", precisaria ser neutra, indicativa e pura. Segundo Bakhtin (op.cit. p.37), “a palavra [...] é neutra em relação a qualquer função ideológica especifica. Pode preencher qualquer espécie de função ideológica: estética, cientifica, moral, religiosa". Para Cavalcante (1997, p.19) "é a palavra que possibilita à consciência abordar verbalmente os signos expressando sua compreensão. É ela, ainda, a expressão viva das relações sociais". Podemos afirmar com isso que a consciência, os signos ideológicos, a palavra não brotam do homem, indivíduo isolado, porém sempre do processo de interação social. Sobre isso fala-nos Bakhtin (op. cit. p.35): 
a consciência adquire forma e existência nos signos criados por um grupo organizado no curso de suas relações sociais. Os signos são o alimento da consciência individual, a matéria de seu desenvolvimento, e ela reflete sua lógica e suas leis. A lógica da consciência é a lógica da comunicação ideológica.

Continuaremos ao longo deste trabalho utilizando as categorias já mencionadas na perspectiva bakhtiniana, com os quais estaremos desenvolvendo uma permanente interlocução, sempre que a entendermos necessária. Como já explicitamos acima, também faremos algumas considerações sobre ideologia no que se refere às concepções do húngaro Georg Lukács, buscando estabelecer um diálogo com Bakhtin para acentuar o lugar do qual falamos aqui.

Para o filosofo húngaro, acentua Lessa (1996, p.54), "a ideologia é uma função social". Isso porque, segundo Lessa (idem, p.54), "o que faz de uma ideação uma ideologia é sua capacidade em conferir sentido às necessidades colocadas pela sociabilização, em dado momento da vida social, através da construção de uma interpretação global da vida, de uma visão de mundo".

Nessa perspectiva, para que as sociedades consigam organizar a sua práxis social de acordo com as necessidades concretas de produção e reprodução dessa existência social, é indispensável uma visão de mundo, uma interpretação global da vida que cumpra uma função social. E é essa função social que cabe à ideologia no sentido amplo, genérico. Essa função social é oriunda da necessidade de o indivíduo compreender o mundo em que vive e indispensável para a sua sobrevivência como ser social.

Além dessa perspectiva no que tange à ideologia, no sentido amplo, também ocorre a ideologia no interior das relações sociais que abrangem as determinações de classe. Assim, como havíamos dito anteriormente quando 
nos referimos à luta de classes, também nelas existem determinações materiais que articulam e caracterizam visões de mundo em conflito, interesses materiais opostos, antagônicos. Daí que, segundo Lukács (1978, p.5), “a produção e reprodução da existência dos homens em sociedade é um processo que se dá a partir de posições teleológicas que são uma especificidade do ser social". É das posições teleológicas "secundárias" que se instituem mecanismos de orientação para as relações entre os homens, no processo de produção e reprodução da vida. É o que afirma Lukács (1978, p.5),

o homem torna-se um ser que dá respostas, precisamente na medida em que - paralelamente ao desenvolvimento social e em proporção crescente - ele generaliza, transformando em perguntas seus próprios carecimentos e suas possibilidades de satisfazê-los; e, quando, em sua resposta ao carecimento que a provoca, funda e enriquece a própria atividade com tais mediações, freqüentemente bem articuladas.

Aí, a ideologia é entendida, como diz Vaisman (1989, p.18), "enquanto veículo de conscientização e prévia-ideação da prática social dos homens". Essa conceituação de ideologia apóia-se na noção de homem como um ser que responde às demandas postas pela realidade objetiva.

Para Althusser (1987, p.88), a ideologia é falsa consciência, conforme expressa esse autor quando diz que "toda ideologia representa, em sua deformação necessariamente imaginária, não são as relações de produção existentes [...], mas sobretudo, a relação (imaginária) dos indivíduos com as relações de produção e demais relações daí derivadas". Temos aí, na opinião de Vaisman, uma posição que assume o "critério gnosiológico na determinação do que é ideologia". Para Bakhtin ideologia corresponde à "expressão de uma tomada de 
posição" (MIOTELLO, 2005), ou ainda, como definiu Volochinov (apud MIOTELLO 2005, p.169), "o conjunto de reflexos e das interpretações da realidade social e natural que tem lugar no cérebro do homem e se expressa por meio de palavras [...] ou outras forma sígnicas".

Para Lukács, que analisa o fenômeno numa perspectiva ontológica, a ideologia cumpre uma função social. Lukács (mimeo) afirma que "a ideologia é acima de tudo aquela forma de elaboração ideal da realidade que serve para tornar a práxis social dos homens consciente e operativa".

Nossa posição está amparada na concepção de ideologia desenvolvida por Bakhtin e Lukács, representando assim um primeiro rompimento com o marxismo althusseriano e a sua definição de ideologia. É nessa perspectiva que desenvolvemos tal rompimento, não sendo ele em definitivo uma forma de distanciamento da $\mathrm{AD}$, nem tampouco das contribuições de Michel Pêcheux.

$\mathrm{Na}$ Análise do Discurso, a ideologia manifesta-se a partir do lugar social do sujeito, com o qual ele se identifica e a partir do qual ele se expressa. Nesse sentido, podemos afirmar que a possibilidade de atribuir sentido através do discurso não corresponde a nenhum arcabouço gramatical, lexical e sintático. Nas palavras de Pêcheux (apud CAVALCANTE 2005, p.21), o sentido "é determinado pelas posições ideológicas que estão em jogo no processo sócio-histórico, no qual as palavras, expressões e proposições são produzidas". Essas posições, expressão ideológica de uma formação social que põe em jogo práticas associadas às relações de classe, são denominadas de "formações ideológicas" e constituem matrizes de sentidos comuns a um conjunto de discursos que expressam posições assumidas pelos sujeitos, em diferentes práticas sociais concretas. Segundo Cavalcante (2005, p. 21).

as formações ideológicas são, pois, expressão da estrutura ideológica de uma formação social que 
põe em jogo práticas associadas às relações de classe e constituem matrizes comuns a uma conjunto de discursos que expressão posições assumidas pelos sujeitos, em diferentes práticas sociais concretas.

Os discursos produzidos socialmente estão sempre vinculados a determinadas formações ideológicas que são constituídas por um conjunto complexo de atitudes e representações que, segundo Haroche et alii (1971, p.102),

são constituídas por um conjunto complexo de atitudes e representações que não são nem individuais, nem universais, mas dizem respeito às posições de classe em conflito. São elementos susceptíveis de intervir como uma força confrontada com outras forças na conjuntura ideológica de uma formação social em um momento dado.

As Formações Ideológicas são, pois, como já dissemos, expressão da estrutura ideológica de uma formação social que põe em jogo práticas associadas às relações de classe. Daí a necessidade de buscar desvelar, em qualquer discurso, suas condições de produção e a formação ideológica a partir da qual ele produz sentido, pois a classe dominante busca imprimir a seu discurso a idéia de neutralidade ou de consenso acima das diferenças de classe, na tentativa de ocultar e/ou abafar os conflitos que são travados permanentemente. Bakhtin (2004, p. 47) já nos faz esse alerta quando afirma que "a classe dominante tende a conferir ao signo ideológico um caráter intangível e acima das diferenças de classe".

\section{Rompendo as amarras}

De acordo com Orlandi (2005, p.19), "nos anos 60, a Análise do Discurso se constitui no espaço de questões criadas pela relação entre três domínios disciplinares que são ao mesmo tempo uma ruptura com o século XIX: a Lingüística, o Marxismo e a Psicanálise”. É o que Pêcheux 
(1988, p. 293) chamava de "Tríplice aliança, que na França ao menos, se configurou sob os nomes de Althusser, Lacan e Saussure no decorrer dos anos 60". O momento histórico característico do nascedouro da Análise do Discurso é, de certo modo, um dos mais caros à teoria marxista.

Nesse período, na Europa, um número expressivo de intelectuais marxistas, fundamentados nas teses estruturalistas, desenvolvia reflexões que, submetidas (conscientemente ou não) e limitadas àquele período, buscavam ao mesmo tempo explicar e defender o fenômeno stalinista e o processo que ocorria na URSS, que consolidou uma teoria distorcida de socialismo, amparada no que se convencionou chamar de "marxismo vulgar". Mesmo os teóricos críticos e de oposição daquele movimento não escaparam ilesos do processo que se consubstanciou na aplicação do estruturalismo à teoria marxista.

No momento de conformação da Análise do Discurso, então, Michel Pêcheux estava influenciado pela obra de Louis Althusser, um dos expoentes dessa vertente do estruturalismo marxista. Pêcheux desenvolve, portanto, uma teoria imersa nas concepções de ideologia e sujeito desse autor. E é exatamente com esses conceitos de ideologia e de sujeito em que a $\mathrm{AD}$ se ampara inicialmente e com que rompemos.

Na perspectiva do autor de Aparelhos ideológicos do Estado, ser sujeito significa ser interpelado pela ideologia, apresentando-se, pois, um sujeito "assujeitado" às determinações sociais. As determinações históricosociais condicionariam o sujeito, e este não teria opções, escolhas, a não ser aquelas postas e determinadas socialmente. De acordo com Althusser (1985, p.104),

o individuo é interpelado como sujeito (livre) para livremente submeter-se às ordens do Sujeito, para aceitar, portanto (livremente) sua submissão, para que ele "realize por si mesmo" os gestos e atos de sua submissão. Os sujeitos se constituem pela sua sujeição. 
Diferente dessa posição defendida por Althusser, Magalhães (2003, p.74) afirma que "as determinações sociais e os condicionamentos do inconsciente não impedem a criação do novo, que necessariamente terá as marcas desses dois condicionantes". É a essa perspectiva da $\mathrm{AD}$ que nos filiamos.

No nosso entendimento, quando o sujeito enuncia, tem a sensação de estar dizendo algo que é essencialmente seu, único, pertencente a sua individualidade. Isto não é irreal; no entanto, o homem, ao falar, não apenas e simplesmente exterioriza a sua singularidade. E, ainda que assim o fosse, mesmo a subjetividade é também ela produto histórico-social, carregando, por conseguinte, as determinações sociais. O homem, ao mesmo tempo em que sofre a interferência dos condicionantes do inconsciente e das determinações sócio-históricas, também produz o novo, se constrói, deixa a sua marca. Não é ele um operador passivo meramente "assujeitado" às condições históricas postas, à causalidade, pois, ao enunciar, o sujeito o faz dentro de um processo de identificação com uma formação ideológica com a qual dialoga e, em sua resposta, faz escolhas, objetivando-as, e, consciente ou inconscientemente, imprime sua marca, constrói a história.

Assim, podemos afirmar que o discurso não é um efeito da subjetividade a-histórica, mas reflexo da práxis social, portanto, um produto do processo histórico vivo. Ainda que se queira considerar as manifestações do psiquismo isoladas do elemento consciente, ele mesmo é socialmente construído, ou seja, é o psiquismo individual também um conjunto de determinações históricas que, no entanto, não anulam o sujeito na sua individualidade. Não o tornam "assujeitado", nem o fazem senhor absoluto do sentido do discurso.

Ao dizermos que o ser social é um ser que faz escolhas, imprimindo a sua marca na história, não estamos atribuindo a esse ser a condição de onipotente. De acordo com Netto (1981, p. 9), "os homens não fazem a história 
a seu bel-prazer, arbitrariamente: fazem-na em situações muito determinadas, em condições que não escolhem e que escapam a seu controle". Nesse caso, os sujeitos históricos constituem uma complexa e dinâmica posição em face do lugar social que ocupam, inseridos em contextos nos quais suas posições políticas podem representar alterações, mudanças, rupturas, ou mesmo, continuidades. Isso significa dizer, pois, que todo discurso é ideológico, produzido no âmbito de um lugar social, mediante um processo de identificação do sujeito com uma conjuntura sócio-histórica. 


\section{Referências}

ALTHUSSER, Louis. Aparelhos ideológicos de Estado. Rio de Janeiro: Graal, 1985.

AMARAL, M. Virginia Borges. Discurso e relações de trabalho. Maceió: Edufal, 2005.

BAKHTIN, Mikhail. Marxismo e filosofia da linguagem. São Paulo: Hucitec, 2004.

BAKHTIN, Mikhail. Estética da criação verbal. São Paulo: Martins Fontes, 1992.

CAVALCANTE, Maria do Socorro A. de O. Produção de texto na escola: homogeneização do não homogêneo. 1997. Dissertação (Mestrado em Letras)—Centro de Ciências Humanas, Letras e Artes, Universidade Federal de Alagoas, Maceió, 1997.

CAVALCANTE, Maria do Socorro A. de O. Ensino de qualidade e cidadania nos parâmetros curriculares nacionais: o simulacro de um discurso modernizador. 2002. Tese (Doutorado em Letras)-Centro de Ciências Humanas, Letras e Artes, Universidade Federal de Alagoas, Maceió, 2002.

CAVALCANTE, Maria do Socorro A. de O. Cavalcante (Org.). As malhas de discursos (re)veladores. Maceió: Edufal, 2005.

COURTINE, Jean Jacques. Analyse du discours politique (le discours communiste adressé aux chétiens). In: Langages. Paris: Larousse, 1981.

LESSA, S. A ontologia de Lukács. Maceió: Edufal, 1996.

LUKÁCS, George. As bases ontológicas do pensamento e da atividade do homem. Revista - temas de ciências humanas. São Paulo, 1978. 
MAGALHÃES, Belmira Rita Costa. O sujeito do discurso: um diálogo possível e necessário. In: VOESE, Ingo (Org). Linguagem em discurso: subjetividade. Santa Catarina: Unisul, 2003.

MARX, K.; ENGELS, F. A ideologia alemã. São Paulo: Martin Claret, 2004.

MARX, K.; ENGELS, F. Manifesto do partido comunista. São Paulo: Martin Claret, 2004.

MARX, K. A origem do capital São Paulo: Centauro, 2000.

MARX, K. O capital. Rio de Janeiro: Bertrand Brasil, 1988. liv. 1.v. 1.

MARX, K. O capital. Rio de Janeiro: Bertrand Brasil, 1988. liv. 1.v. 2.

MIOTELLO, Vlademir. Ideologia. In: BRAIT, B. (Org.).

Bakhtin: conceitos-chave. São Paulo: Contexto, 2005.

NETTO, J. P. O que é stalinismo. São Paulo: Brasiliense, 1981.

ORLANDI, E. P. Análise de discurso: princípios e procedimentos. São Paulo: Pontes, 2005.

ORLANDI, E. P. (Org.). A leitura e os leitores Campinas: Pontes, 1998.

ORLANDI, E. P. Interpretação: autoria, leitura e efeitos do trabalho simbólico. Petrópolis: Vozes, 1996.

ORLANDI, E. P. As formas do silêncio: no movimento dos sentidos. Campinas: Editora da Unicamp, 1995.

PÊCHEUX, M. Semântica e discurso: uma crítica a afirmação do óbvio. São Paulo: Editora da Unicamp, 1988. 
PÊCHEUX, M. Discurso: estrutura ou acontecimento. São Paulo: Editora da Unicamp, 1990.

VAISMAN, Ester. A ideologia e sua determinação ontológica. Revista Ensaio, São Paulo, nº17/18, 1989. 